\title{
Reduced disorderliness of growth hormone release in biochemically inactive acromegaly after pituitary surgery
}

\author{
Gerrit van den Berg, Steven M Pincus ${ }^{2}$, Marijke Frölich ${ }^{1}$, Johannes D Veldhuis ${ }^{3}$ and Ferdinand Roelfsema \\ Departments of Endocrinology and ${ }^{1}$ Clinical Chemistry, Leiden University Medical Center, Leiden, The Netherlands, ${ }^{2} 990$ Moose Hill Road, Guilford, \\ Connecticut, USA and ${ }^{3}$ Department of Medicine, National Science Foundation Center for Biological Timing, University of Virginia Health Sciences \\ Center, Charlottesville, Virginia 22908, USA
}

(Correspondence should be addressed to F Roelfsema, Department of Endocrinology, Leiden University Medical Center, PO Box 9600 , 2300 RC Leiden, The Netherlands)

\begin{abstract}
The episodicity of $24 \mathrm{~h}$ GH release was studied in 18 patients with active acromegaly, 12 patients 7-10 days after pituitary surgery, 14 patients long after operation (3-17 years), and 21 healthy gender- and age-matched control subjects, using a recently introduced scale- and model-independent regularity statistic, approximate entropy (ApEn). Blood samples were taken at 10-min intervals for $24 \mathrm{~h}$, and plasma GH concentrations were measured by immunofluorometric assay (detection limit $11.5 \mathrm{ng} / \mathrm{l}$ ). For this study we selected operated patients who were biochemically in remission, defined by normal circulating IGF-I and insulin-like growth factor-binding protein-3 (IGFBP-3) concentrations, normal glucose-suppressed plasma GH concentration $(<0.38 \mu \mathrm{g} / \mathrm{l})$, and the normalization of the paradoxical rise of GH to TRH or GnRH. In patients with active acromegaly ApEn was $1.23 \pm 0.04$, with no overlap with the control subjects $\left(P=1.2 \times 10^{-16}\right)$, who had an ApEn of $0.40 \pm 0.04$. ApEn in patients shortly after surgery was $0.71 \pm 0.09$ ( $P<0.001$ vs controls), and long after surgery $0.56 \pm 0.05(P<0.011$ vs controls). ApEn values in treated and untreated patients correlated significantly with the plasma concentration of IGF-I $(r=0.531)$ and IGFBP-3 $(r=0.598)$, and the log-transformed $24 \mathrm{~h} \mathrm{GH}$ secretion rate $(r=0.749)$. Shortly after surgery only one-third of the patients had a normal ApEn value, whereas long after surgery about $70 \%$ of the patients had a normal ApEn value. Although ApEn eventually normalized in about $70 \%$ of the operated patients, the cause of the persistence of abnormal GH release in the remainder of the subjects is not known, and might reflect permanent hypothalamic-pituitary dysfunction or a very early recurrence of the somatotroph adenoma.
\end{abstract}

European Journal of Endocrinology 138 164-169

\section{Introduction}

Growth hormone (GH) secretion in clinically active acromegaly is characterized by increased pulse frequency, and raised basal (nonpulsatile) secretion $(1,2$, 3). Recent studies, applying a new regularity statistic, approximate entropy (ApEn), have revealed that the $\mathrm{GH}$ secretion pattern is also highly irregular $(4,5,6)$. This inference has been supported further by other independent studies showing reduced predictability of $\mathrm{GH}$ release (by an adaptive neural network analysis) in acromegalic patients (7). Irregular and disorganized secretion might be a fundamental feature of endocrine tumors, since it has also been described for aldosteronesecreting adenoma (8), and for adrenocorticotropin (ACTH) and cortisol secretion in patients with Cushing's disease (9). Notably, eight surgically treated acromegalic patients studied by Hartman et al. (4) showed intermediate irregularity, i.e. somewhat increased ApEn values and hence greater disorderliness compared with control subjects, yet with lower values than untreated patients (4). The purpose of the present study was to investigate in a considerably larger group of surgically treated acromegalic patients whether preoperatively disorganized $\mathrm{GH}$ secretion could normalize eventually after treatment. Therefore, we investigated $24 \mathrm{~h} \mathrm{GH}$ profiles 7-10 days after surgery in patients who ultimately remained in clinical and biochemical remission $0.5-5$ years after the operation. In addition, another group of patients, some of whom were studied shortly after surgery, underwent this investigation 3-17 years after the operation. By using this strategy, we could test the potential reversibility of quantifiably increased disorderliness of $\mathrm{GH}$ release in transsphenoidally operated acromegalic patients and concomitantly could evaluate the utility of ApEn as a potential marker of clinical outcome. This work was presented in part at the 4th International Congress of Endocrinology, San Francisco, 1996. 


\section{Patients and methods}

Ten healthy men and 11 healthy women of normal height and body mass index (BMI) served as matched controls for the acromegalic patients. Controls and patients originated from the same community, and were evaluated in an identical sampling paradigm and GH assay (below).

Informed consent was obtained from all subjects and the study was approved by the ethics committee of the Leiden University Medical Center. The age of the male controls was $45 \pm 2.6$ years (mean \pm s.E.M.) and of the female controls $51 \pm 3.7$ years. The three groups of patients investigated included 18 untreated subjects with active acromegaly, 12 patients shortly after successful pituitary microsurgery (i.e. 7-10 days), and 14 patients long after surgery (3-17 years, mean 6.9 years). The control subjects, the patients with untreated acromegaly, and the patients shortly after pituitary surgery had participated in a previous study, in which $\mathrm{GH}$ secretion was measured with a multiparameter deconvolution analysis (3). The follow-up period of the patients who were studied shortly after surgery was 0.5-5.0 years, with a mean of 4.2 years. One patient who had the shortest follow-up period unfortunately died during gastroscopy in a nearby general hospital. All the patients had a normal suppressed $\mathrm{GH}$ concentration $(<0.38 \mu \mathrm{g} / \mathrm{l}$ or $<1 \mathrm{mU} / \mathrm{l})$ during glucose loading in yearly studies. In addition, in all operated patients paradoxical reactions of $\mathrm{GH}$ to thyrotropin-releasing hormone (TRH) and/or gonadotropin-releasing hormone (GnRH) normalized. The ages of the various patient groups and their BMIs are listed in Table 1. Not unexpectedly, BMI was increased in the acromegalic patients, irrespective of their GH secretory status, since body composition in patients with active acromegaly is characterized by increases in total body weight, extracellular water, and lean body mass, and decreased fat mass, compared with healthy height-adjusted controls $(10,11)$. In patients after surgical treatment, and in clinical and biochemical remission, body weight and BMI remained unchanged. This was accounted for by an increase of body fat to normal values, and a decrease of extracellular water and decrease of lean body mass.

None of the treated or untreated acromegalic patients used hormone substitution therapy with the exception of a female patient, who was treated surgically for papillary thyroid cancer 10 years before the acromegaly was discovered and received thyroid hormone treatment. The postmenopausal women (five controls, four patients shortly after surgery, and four long after surgery) studied here did not use estrogen therapy. Patients and volunteers were hospitalized the evening before the sampling studies. On the following morning, an indwelling i.v. cannula was inserted in a large vein of the forearm, and blood samples were withdrawn at 10-min intervals starting at $0900 \mathrm{~h}$ and for the next $24 \mathrm{~h}$. A slow i.v. infusion of $0.9 \% \mathrm{NaCl}$ and heparin $(1 \mathrm{U} / \mathrm{ml})$ was used to keep the line open. The subjects were free to move around, but not to sleep, during the daytime. Meals were served at 0800, 1230 and $1730 \mathrm{~h}$. Lights were turned off between 2200-2400 h, depending on the sleeping habits of the patient. No sleep monitoring was carried out. Premenopausal female control subjects were studied in the early follicular phase of the menstrual cycle.

The endocrine tests performed in the patients before and after surgery, and during follow-up studies, included an oral $75 \mathrm{~g}$ glucose tolerance test, and bolus corticotropin-releasing hormone (CRH), TRH and GnRH tests on separate days. In the surgically treated patients the mean nadir plasma $\mathrm{GH}$ concentration during the glucose tolerance test was $0.13 \pm 0.02 \mu \mathrm{g} / \mathrm{l}$ (range $0.015-0.37 \mu \mathrm{g} / \mathrm{l}$ ). Paradoxical GH increases to TRH and/or GnRH, defined as a doubling of the basal GH concentration and an incremental increase above $1.9 \mu \mathrm{g} / \mathrm{l}$, were absent after surgery in all patients. Patients with active acromegaly had an elevated circulating $\mathrm{GH}$ concentration during oral glucose loading (mean $31.0 \pm 6.9 \mu \mathrm{g} / \mathrm{l}$, range $7.3-113 \mu \mathrm{g} / \mathrm{l}$ ). The plasma IGF-I concentration was increased in these patients (mean $59 \mathrm{nmol} / \mathrm{l}$, range $35-118 \mathrm{nmol} / \mathrm{l}$ ).

\section{Assays}

Plasma GH was measured with a sensitive time-resolved fluoro-immunoassay (Wallac, Turku, Finland). The assay is specific for the $22 \mathrm{kDa} \mathrm{GH}$. The standard was biosynthetic recombinant human GH (Genotropin, Pharmacia Upjohn, Uppsala, Sweden), and was calibrated against the WHO First International Reference Preparation 80/505 (to convert $\mu \mathrm{g} / \mathrm{l}$ to $\mathrm{mU} / \mathrm{l}$, multiply

Table 1 Clinical and biochemical characteristics (mean \pm S.E.M.) of the control subjects and patients.

\begin{tabular}{|c|c|c|c|c|c|c|}
\hline & $\begin{array}{c}\text { Number of } \\
\text { subjects }\end{array}$ & $\begin{array}{c}\text { Age } \\
\text { (years) }\end{array}$ & $\begin{array}{c}\text { BMI } \\
\left(\mathrm{kg} / \mathrm{m}^{2}\right)\end{array}$ & $\begin{array}{l}\text { IGF-I } \\
(\mathrm{nmol} / \mathrm{l})\end{array}$ & $\begin{array}{c}\text { IGFBP-3 } \\
(\mathrm{nmol} / \mathrm{l})\end{array}$ & $\begin{array}{l}\text { GH secretion } \\
\left(\mu \mathrm{g} / \mathrm{I}_{\mathrm{v}} / \text { day }\right)\end{array}$ \\
\hline Controls & 21 & $48.5 \pm 2.4$ & $23.9 \pm 0.7$ & $18.1 \pm 1.5$ & $82 \pm 5.6$ & $30 \pm 4.6$ \\
\hline Patients shortly after surgery & 12 & $49.0 \pm 3.6$ & $27.7 \pm 0.9^{a}$ & $20.7 \pm 1.3$ & $95 \pm 4.2$ & $35 \pm 5.4$ \\
\hline Patients long after surgery & 14 & $55.0 \pm 2.6$ & $28.1 \pm 1.1^{a}$ & $14.9 \pm 1.3$ & $79 \pm 4.6$ & $35 \pm 6.9$ \\
\hline Untreated patients & 18 & $50.6 \pm 3.1$ & $27.1 \pm 1.0^{\mathrm{a}}$ & $59.8 \pm 6.4^{b}$ & $164 \pm 8.4^{c}$ & $1620 \pm 410^{d}$ \\
\hline
\end{tabular}

Statistical differences between patients and control subjects, ${ }^{a} P<0.001,{ }^{b} P<0.0001,{ }^{c} P<0.0005$ (Student's $t$-test);

${ }^{\mathrm{d}} P<0.01$ (Wilcoxon test). 
by 2.6). The limit of detection (defined as the value 2 s.D. above the mean value of the zero standard) was $11.5 \mathrm{ng} / \mathrm{l}$. The intraassay coefficient of variation varied from $1.6-8.4 \%$ in the assay range from $0.1-18 \mu \mathrm{g} / \mathrm{l}$ $(0.26-47 \mathrm{mU} / \mathrm{l})$, and the interassay coefficient of variation was $2.0-9.9 \%$ in the same range. The total plasma IGF-I concentration was measured by RIA (Incstar, Stillwater, MN, USA), after extraction and purification (12). The interassay coefficient of variation was less than $11 \%$. The limit of detection was $1.5 \mathrm{nmol} / \mathrm{l}$. Normal values are $9.0-34.0 \mathrm{nmol} / \mathrm{l}$ for subjects aged 30-50 years, $8.0-27.0 \mathrm{nmol} / \mathrm{l}$ for those aged $50-70$ years, and $8.0-22.0 \mathrm{nmol} / \mathrm{l}$ for those aged 70 years or more. Plasma IGFBP-3 concentration was measured by RIA (Nichols Institute Diagnostics, San Juan Capistrano, CA, USA). The interassay coefficient of variation was below $6.8 \%$ at different concentrations. The limit of detection was $2.8 \mathrm{nmol} / \mathrm{l}$. Normal values are $45.6-$ $122 \mathrm{nmol} / \mathrm{l}$ for subjects aged 30-50 years, and 49.0$112 \mathrm{nmol} / \mathrm{l}$ for subjects between $50-70$ years.

\section{Deconvolution analysis}

Multiple parameter deconvolution was used to estimate various specific measures of hormone secretion and half-life from all plasma hormone concentrations and their dose-dependent intrasample variances considered simultaneously (13). Total production is the sum of basal production and pulsatile production, which were estimated as described $(14,15)$.

\section{Approximate entropy, quantification of episodicity}

The regularity or orderliness of $\mathrm{GH}$ release over $24 \mathrm{~h}$ was quantified by an approximate entropy statistic, ApEn $(5,6,16,17)$. ApEn provides a relative measure of pattern repetition within the hormone profile by assigning a single (positive) number whose value increases with greater disorder or more irregularity. This statistic exhibits high sensitivity $(>90 \%)$ and specificity $(>90 \%)$ in distinguishing the relative orderliness of GH, aldosterone, and ACTH release in normal vs tumoral secretory profiles and in the case of GH, in healthy men compared with women $(4,8,9,18)$. For the GH time series each comprising 145 observations, we used $\operatorname{ApEn}(1,20 \%)$ and $\operatorname{ApEn}(2,20 \%)$ as a scale- and model-independent statistic calculated for window lengths $(m)$ of 1 and 2 respectively, and a tolerance $(r)$ of $20 \%$ of the overall S.D. of the individual subject's $24 \mathrm{~h}$ serum GH concentration profile. Adjusting the tolerance to each subject's series S.D. normalizes ApEn to otherwise unequal mean hormone levels.

\section{Statistical analysis}

Data are given as the mean \pm s.E.M., unless otherwise mentioned. Statistical analyses were done by using

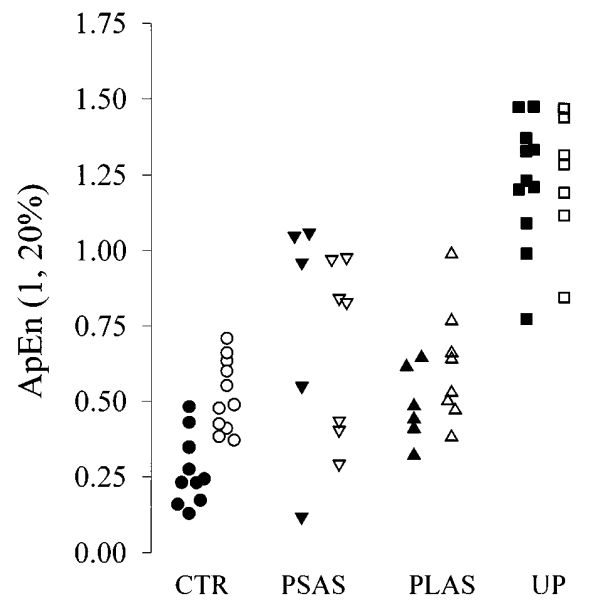

Figure $1 \mathrm{ApEn}(1,20 \%)$ values in controls, surgically treated patients and active untreated acromegalic patients. Open symbols are female subjects and closed symbols males. CTR = controls; PSAS = patients shortly after surgery; PLAS = patients long after surgery; UP = untreated active acromegalics.

ANOVA, regression techniques, and Student's $t$-test for paired and non-paired data. Statistical results were corroborated by non-parametric tests. Calculations were made with SPSS Windows version 7.0 and with Systat, version 6 (SPSS Inc., Chicago, IL, USA). $P<0.05$ was considered significant.

\section{Results}

In 10 healthy male controls, $\operatorname{ApEn}(1,20 \%)$ was $0.27 \pm 0.04$, and in 11 female controls $0.52 \pm 0.04$. In untreated patients with active acromegaly $\operatorname{ApEn}(1,20 \%)$ was highly significantly increased, with complete separation of the active acromegalic group and the sex- and age-matched controls (see Fig. 1 and Table 2. In 11 untreated male patients $\operatorname{ApEn}(1,20 \%)$ was $1.22 \pm 0.06\left(P=2.12 \times 10^{-10}\right)$, and in 7 untreated female patients $1.24 \pm 0.08\left(P=8.3 \times 10^{-8}\right)$. Shortly after surgery, $\operatorname{ApEn}(1,20 \%)$ was $0.74 \pm 0.18$ in 5 male patients $(P=0.004)$ and $0.62 \pm 0.06$ in 7 female patients $(P=0.12)$. Long after surgery $\operatorname{ApEn}(1,20 \%)$ was $0.48 \pm 0.05$ in 6 male patients $(P=0.004)$ and $0.68 \pm 0.11$ in 8 female patients $(P=0.19)$. For

Table 2 ApEn(1,20\%) values (mean \pm S.E.M.) in controls and acromegalic patients.

\begin{tabular}{lcc}
\hline & Males & Females \\
\hline Controls & $0.27 \pm 0.04$ & $0.52 \pm 0.04$ \\
Patients shortly after surgery & $0.74 \pm 0.18^{\mathrm{a}}$ & $0.68 \pm 0.11^{\mathrm{b}}$ \\
Patients long after surgery & $0.48 \pm 0.05^{\mathrm{a}}$ & $0.62 \pm 0.07^{\mathrm{b}}$ \\
Untreated patients & $1.22 \pm 0.06^{\mathrm{c}}$ & $1.24 \pm 0.08^{\mathrm{c}}$ \\
\hline
\end{tabular}

Statistical comparisons were made between sex-matched controls and the patient groups with the two-tailed Student's $t$-test.

${ }^{\mathrm{a}} P=0.004,{ }^{\mathrm{b}} \mathrm{NS},{ }^{\mathrm{c}} P<10^{-7}$. 
$\operatorname{ApEn}(2,20 \%)$, comparable statistical results were obtained (data not shown). In the ANOVA of ApEn the only significant factor was the subject group, i.e. controls and the various groups of patients, as outlined in the Methods section, but not the sex of the individuals or the interaction between these two categorical variables and therefore the ApEn values for the combined groups are also calculated. The mean $\operatorname{ApEn}(1,20 \%)$ in control subjects was $0.40 \pm 0.04$, in active acromegaly $1.23 \pm$ $0.04\left(P=1.2 \times 10^{-16}\right.$ vs controls), shortly after surgery $0.71 \pm 0.09(P=0.001$ vs controls $)$, and $0.56 \pm 0.05$ longer after surgery $(P=0.011$ vs controls). Comparable statistical results were obtained for $\operatorname{ApEn}(2,20 \%)$ (data not shown). The circulating plasma concentrations of IGF-I and IGFBP-3 and the total $24 \mathrm{~h} \mathrm{GH}$ secretion rate expressed per liter distribution volume $\left(l_{V}\right)$ of the controls and patients are listed in Table 1. No significant differences were present in circulating concentrations of IGF-I and IGFBP-3 between controls and treated patients. This was also true for the $\mathrm{GH}$ secretion rate per $24 \mathrm{~h}$. In active acromegaly $\mathrm{GH}$ production was increased 50 -fold, plasma IGF-I concentration 3-fold, and plasma IGFBP-3 concentration 2 -fold.

In Fig. 2 the ApEn(1,20\%) values for the surgically treated patients are plotted against the glucosesuppressed GH concentration. In addition, the figure also shows the upper normal limits (mean +2 s.D.) for $\operatorname{ApEn}(1,20 \%)$ in males and females $(0.50$ and 0.70 respectively). Only one of the five male subjects who were investigated a week after surgery had a normal $\operatorname{ApEn}(1,20 \%)$, but in females three out of seven had reached a normal $\operatorname{ApEn}(1,20 \%)$. In contrast, long (317 years) after surgery, most subjects had ApEn values

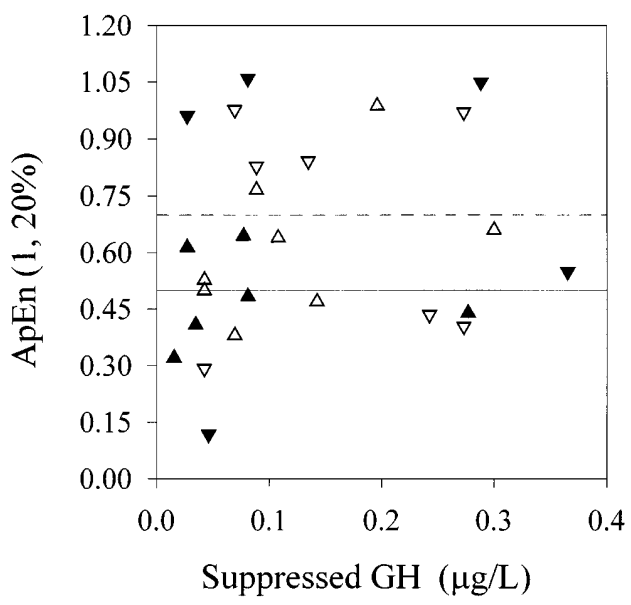

Figure 2 Relationship between the suppressed serum GH concentrations obtained during the oral glucose tolerance test and ApEn(1,20\%). Normal suppressed GH concentration, in our healthy controls, is less than $0.38 \mu \mathrm{g} / \mathrm{l}$ (to convert this value to $\mathrm{mU} / \mathrm{l}$ multiply by 2.6). Horizontal lines refer to the upper normal limits of ApEn(1,20\%): 0.5 for males and 0.7 for females. $\nabla, \nabla$ patients shortly after surgery; $\boldsymbol{\Lambda}, \triangle$ patients long after surgery. Open symbols are female subjects and closed symbols males. within a normal control range, and only two female and two male subjects retained elevated ApEn values. As well, three other (non-cured) patients (two male and one female), who also underwent the sampling study shortly after surgery, but who did not normalize in terms of glucose-suppressed $\mathrm{GH}(0.37,0.41$ and $0.85 \mu \mathrm{g} / \mathrm{l})$ or still had a paradoxical rise to TRH, showed increased $\operatorname{ApEn}(1,20 \%)$ values of $1.17,0.78$ and 0.79 respectively.

A subgroup of six patients underwent a $24 \mathrm{~h}$ sampling study both immediately and later after surgery (two male and four female patients). The mean ApEn(1,20\%) for this subgroup was $0.79 \pm 0.10$ shortly after surgery, and $0.57 \pm 0.10$ long after surgery. Although the mean ApEn became lower, the difference was statistically not significant $(P=0.17$ in the two-tailed Student's $t$-test). The daily GH production rates were similar at both times, namely $30.0 \pm 5.0 \mu \mathrm{g} / \mathrm{l}_{\mathrm{v}}$ and $36.0 \pm 9.2 \mu \mathrm{g} / \mathrm{l}_{\mathrm{v}} \quad(P=$ 0.509 ), and this was also true for the circulating concentrations of IGF-I and IGFBP-3. Plasma IGF-I and IGFBP-3 concentrations shortly after surgery were $19.8 \pm 0.7 \mathrm{nmol} / \mathrm{l}$ and $88.0 \pm 5.6 \mathrm{nmol} / \mathrm{l}$ respectively, and during follow-up $17.5 \pm 1.9 \mathrm{nmol} / \mathrm{l}$ and $85.2 \pm$ $5.9 \mathrm{nmol} / \mathrm{l}$ (not statistically significant).

Finally, we also explored the relationship between ApEn and the circulating concentrations of IGF-I, IGFBP-3, and the $24 \mathrm{~h}$ secretion rate of $\mathrm{GH}$ for treated and untreated patients. The correlation coefficients between $\operatorname{ApEn}(1,20 \%)$ and IGF-I, IGFBP-3 and the log $\mathrm{GH}$ production rate were $0.531,0.598$, and 0.749 respectively. The statistical significance of these regressions was high, and the $P$ values were less than 0.0001 . In Fig. 3 the relationship between $\operatorname{ApEn}(1,20 \%)$ and the $\mathrm{GH}$ production rate is shown for untreated and treated acromegalic patients, clearly depicting the increase of ApEn with higher $\mathrm{GH}$ production.

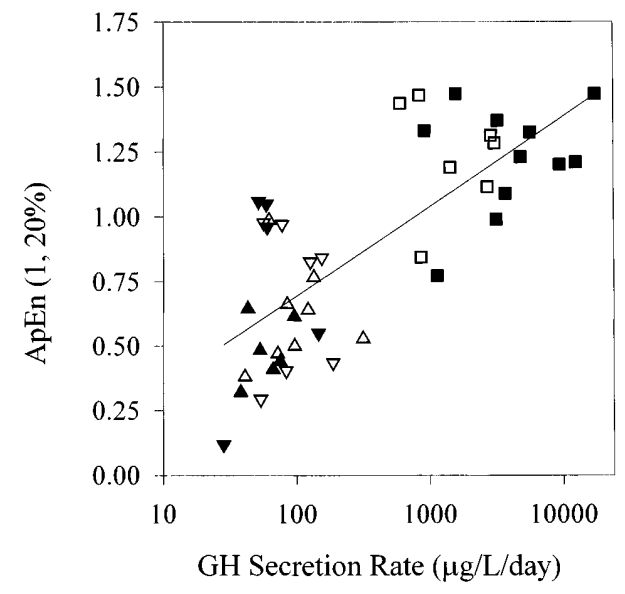

Figure 3 Relationship between the calculated daily GH secretion rate, determined by deconvolution analysis, and $\operatorname{ApEn}(1,20 \%) . \mathbf{\square}, \square$ patients with active acromegaly; $\boldsymbol{\nabla}, \nabla$ patients shortly after surgery; $\boldsymbol{\Delta}, \Delta$ patients long after surgery. Open symbols are female subjects and closed symbols males. The regression line is shown; the correlation coefficient was $0.749, P<0.0001$. 


\section{Discussion}

The present study first confirms earlier data by Hartman et al. (4) that GH release in active acromegaly is more markedly disorderly or irregular compared with normals, as demonstrated by highly increased ApEn values. In the study of Hartman and colleagues, the number of treated patients was small, they had circulating IGF-I concentrations in the high normal range of young adults and no clinical follow-up data were provided. Furthermore, some of these patients also underwent radiation therapy. Therefore that group of patients might not have been completely in remission, in contrast to our selected group of patients in whom long-term GH data were used to define their GH status both shortly and long after surgery. In addition, none of our patients underwent postsurgical radiation therapy, and none had partial or complete pituitary failure before and after operation. Therefore, several potential confounding factors on ApEn were excluded. As described previously, ApEn was larger in females than in males $(4,18)$. After microsurgery, even in the early postoperative period, ApEn values in our patients in biochemical remission were significantly lower than in active acromegaly, indicating greater regularity of $\mathrm{GH}$ release. One-third of the operated patients had an ApEn value in the normal range for age and gender soon after surgery. Long after surgery, ApEn values were normal in $70 \%$ of the patients, all of whom were carefully selected in terms of potential permanent cure. Each showed normal glucosesuppressed GH concentrations below $0.38 \mu \mathrm{g} / \mathrm{l}(1 \mathrm{mU} / \mathrm{l})$, not only at the time of the $24 \mathrm{~h}$ sampling study, but also during follow-up studies. In addition, paradoxical reactions of GH toward TRH and/or GnRH were normalized, and this was also true for the circulating concentrations of IGF-I and IGFBP-3. By using these strict criteria, we are convinced that the investigated patients were in biochemical remission and that therefore the slightly raised ApEn values in some patients do not point necessarily to a very early recurrence of the disease.

We observed a tendency for lower ApEn values in paired comparisons of patients studied twice (early and late) after surgery, but the difference was not statistically significant because of the limited number of patients. This observation might indicate, in the absence of pituitary deficiencies, that surgery as such, or other, non-specified, postoperative factors might influence the regularity of GH release. This is supported by the observation that the $\mathrm{GH}$ production rate and GH-dependent proteins such as IGF-I and IGFBP-3 were normalized after surgery, and remained stable in this subgroup. At present, however, we cannot prove or refute a non-specific influence of pituitary surgery, since neither we nor others have studied GH secretion profiles in patients with non-GH secreting adenomas after pituitary surgery.

The mechanism underlying the decreased regularity (i.e. increased disorderliness) of $\mathrm{GH}$ secretion in acromegaly is not established, but probably reflects loss of within-axis network coherence, reduced feedback control, and/or greater complexity of biochemical input to the tumoral secretory pathway. The present data do not allow a distinction among these possibilities. Several clinical observations have suggested that $\mathrm{GH}$ pulses in this disease are generated probably within the tumor, rather than from physiological input signals such as growth hormone-releasing hormone (GHRH) and somatostatin $(1,3,4,19)$. Further evidence for the tumoral origin of pulses was obtained by others in in vitro data of adenoma tissue, which exhibits episodic $\mathrm{GH}$ release in the absence of hypothalamic GHRH and somatostatin $(20,21)$. The presence of a pituitary tumor per se does not decrease the regularity of $\mathrm{GH}$ secretion, since we have observed normal ApEn values for plasma $\mathrm{GH}$ profiles in five patients with untreated prolactinomas (unpublished data). By using a system of multiple neural networks, acting in parallel (adaptive mixtures of local experts), Prank and coworkers (7) could distinguish normal controls from active acromegalics and octreotide-treated patients, and their results corroborate our present data.

The approximate entropy in acromegalic patients correlated highly significantly with the GH secretion rate, and somewhat less with the circulating concentrations of IGF-I and IGFBP-3. The regression analysis was significant when all acromegalics, surgically treated and non-treated, were considered together, but not when analyzed separately. A clear dissociation between unchanging ApEn values (data not shown), GH secretion rates and circulating IGF-I concentrations was observed in a previously reported series of acromegalic patients treated with octreotide (22). Therefore, the relationship as discussed above depends more on the presence of an adenoma than on $\mathrm{GH}$ concentration per se or other potentially confounding factors such as gender and age. In our normal controls, ApEn did not correlate with the $24 \mathrm{~h} \mathrm{GH}$ secretion rate or the mean plasma GH concentration, indicating that ApEn in healthy subjects does not depend on $\mathrm{GH}$ production rate. In fact, it has been demonstrated that with increasing age and adiposity as plasma GH concentrations fall, ApEn levels increase (23-25). Finally, although we had expected normal ApEn values in all our patients in biochemical remission long after surgery, since they all had a normal total daily GH secretion rate, normal basal GH release, low interpulse serum $\mathrm{GH}$ concentrations, suppressed GH concentrations following glucose loading, and loss of anomalous responses to hypothalamic peptides, this was not found in four patients. These patients did not differ from the other treated subjects in terms of tumor size, severity or duration of the disease, or gonadal status. This observation might therefore point to a permanent derangement of the hypothalamus by unknown factors, altered intrapituitary architecture with disrupted paracrine regulation or the possibility of remarkably delayed 
tumor recurrence. A determination of whether the persistence of increased values of ApEn postoperatively in clinically inactive acromegalic patients reflects continued hypothalamic-pituitary disregulation or presages delayed tumor recurrence will require extended biochemical and clinical follow-up in such patient populations.

\section{References}

1 Hartman ML, Veldhuis JD, Vance ML, Faria ACS, Furlanetto RW \& Thorner MO. Somatotropin pulse frequency and basal concentrations are increased in acromegaly and are reduced by successful therapy. Journal of Clinical Endocrinology and Metabolism 199070 1375-1384.

2 Barkan AL, Stred SE, Reno K, Markows M, Hopwood NJ, Kelch RP \& Beitins IZ. Increased growth hormone pulse frequency in acromegaly. Journal of Clinical Endocrinology and Metabolism 1989 64 1225-1233.

3 Van den Berg G, Frölich M, Veldhuis JD \& Roelfsema F. Growth hormone secretion in recently operated acromegalic patients. Journal of Clinical Endocrinology and Metabolism 199479 1706-1715.

4 Hartman ML, Pincus SM, Johnson ML, Hunter Matthews D, Faunt LM, Vance LM et al. Enhanced basal and disorderly growth hormone secretion distinguish acromegalic from normal pulsatile growth hormone release. Journal of Clinical Investigation 199494 1277-1288.

5 Pincus SM. Approximate entropy as a measure of system complexity. Proceedings of the National Academy of Sciences of the USA 199188 2297-2301.

6 Pincus SM \& Singer BH. Randomness and degrees of irregularity. Proceedings of the National Academy of Sciences of the USA 199693 2083-2088.

7 Prank K, Kloppstech M, Nowlan SJ, Sejnowski TJ \& Brabant G. Self-organized segmentation of time series: separating growth hormone secretion in acromegaly from normal controls. Biophysical Journal $1996702540-2547$.

8 Van den Berg G, Pincus SM, Veldhuis JD, Frölich M \& Roelfsema F. Greater disorderliness of ACTH and cortisol release accompanies pituitary-dependent Cushing's disease. European Journal of Endocrinology $1997136394-400$.

9 Siragy HM, Vieweg WVR, Pincus S \& Veldhuis JD. Increased disorderliness and amplified basal and pulsatile aldosterone secretion in patients with primary aldosteronism. Journal of Clinical Endocrinology and Metabolism 199580 28-33.

10 Bengtsson B-Å, Brummer RJM, Edén S \& Bosaeus I. Body composition in acromegaly. Clinical Endocrinology 198930 121-130.

11 Brummer RJM, Lönn L, Kvist H, Grangård U, Bengtsson B- $\AA$ \& Sjöström L. Adipose tissue and muscle volume determination by computed tomography in acromegaly, before and one year after adenomectomy. European Journal of Clinical Investigation 199323 199-205.
12 Roelfsema F, Frölich M \& van Dulken H. Somatomedin-C levels in treated and untreated patients with acromegaly. Clinical Endocrinology 198726 137-144.

13 Veldhuis JD \& Johnson ML. Deconvolution analysis of hormone data. Methods in Enzymology 1992210 539-575.

14 Roelfsema F, van den Berg G, Frölich M, Veldhuis JD, van Eijk A, Buurman MM et al. Sex-dependent alteration in cortisol response to endogenous adrenocorticotropin. Journal of Clinical Endocrinology and Metabolism 199377 234-240.

15 Veldhuis JD, Moorman J \& Johnson ML. Deconvolution analysis of neuroendocrine data: waveform-independent methods and applications. Methods in Neurosciences 199420 279-325.

16 Pincus SM, Gladstone IM \& Ehrenkranz RA. A regularity statistic for medical data analysis. Journal of Clinical Monitoring 19917 335-345.

17 Pincus SM \& Goldberger AL. Physiological time-series analysis: what does regularity quantify? American Journal of Physiology 1994266 H1643-H1656.

18 Pincus SM, Gevers EF, Robinson ICAF, van den Berg G, Roelfsema F, Hartman ML et al. Females secrete growth hormone with more process irregularity than males in both humans and rats. American Journal of Physiology 1996270 E107-E115.

19 Riedel M, Gunther T, von zur Muhlen A \& Brabant G. The pulsatile $\mathrm{GH}$ secretion in acromegaly: hypothalamic or pituitary origin? Clinical Endocrinology 199237 233-239.

20 Stewart JK, Clifton DK, Koerker DJ, Rogol AD, Jaffe T \& Goodner CJ. Pulsatile release of growth hormone and prolactin from the primate pituitary in vitro. Endocrinology $19851161-5$.

21 Joubert (Bression) D, Benlot C, Lagoguey A, Garnier AP, Brandi AM, Gautron JP et al. Normal and growth hormone (GH)-secreting adenomatous human pituitaries release somatostatin and GHreleasing hormone. Journal of Clinical Endocrinology and Metabolism $198968572-577$.

22 Roelfsema F, de Boer H \& Frölich M. The influence of octreotide treatment on pulsatile growth hormone release in acromegaly. Clinical Endocrinology 199033 297-306.

23 Veldhuis JD, Liem AY, South S, Weltman A, Weltman J, Clemmons DA et al. Differential impact of age, sex steroid hormones, and obesity on basal versus pulsatile growth hormone secretion in men as assessed in an ultrasensitive chemiluminescence assay. Journal of Clinical Endocrinology and Metabolism 199580 32093222.

24 Friend K, Iranmanesh A \& Veldhuis JD. The orderliness of growth hormone $(\mathrm{GH})$ release process and the mean mass of $\mathrm{GH}$ secreted per burst are highly conserved in individual men on successive days. Journal of Clinical Endocrinology and Metabolism 199681 3746-3753.

25 Vahl N, Jorgensen JO, Skjaerback C, Veldhuis JD, Orskov H \& Christiansen JS. Abdominal adiposity rather than age and sex predicts mass and regularity of $\mathrm{GH}$ secretion in healthy adults. American Journal of Physiology 1997272 E1108-E1116.

Received 30 June 1997

Accepted 13 October 1997 